\title{
COMPARAÇÕES FÍSICAS DE UM LATOSSOLO VERMEIHO ESCURO SOB DIFERENTES PERÍODOS DE CULTIVO EM SISTEMA DE PLANTIO DIRETO
}

\author{
Dark Red Oxissoil Physical Comparisons Under Different \\ Periods of Culture in Direct Soil System
}

\author{
Renato Tratch ${ }^{1}$ \\ Beatriz Mont Serrat ${ }^{2}$ \\ Tatiana Bogo Montans ${ }^{3}$ \\ Airton Rodrigues Pinto Júnior ${ }^{4}$
}

\section{Resumo}

Com o aumento dos anos de implantação do sistema de plantio direto, características físicas do solo, como a densidade, macroporosidade, microporosidade e porosidade total, são alteradas, sendo escassos estudos que avaliam vários anos de implantação desse sistema, em diversos tipos de solos. O objetivo deste trabalho foi comparar as características físicas de um Latossolo Vermelho Escuro sob diferentes períodos de instalação do sistema de plantio direto com uma área controle sob mata nativa, na região de Campo Mourão, Paraná. A coleta dos dados foi realizada em quatro áreas, de um hectare, com 10, 20 e 30 anos de implantação do sistema de plantio direto e uma de mata nativa. As amostras intactas para a análise física foram retiradas nas profundidades de 0 - 5; 5 - 10; 10 - 15; e 15 - $20 \mathrm{~cm}$. Observou-se que, na área com 30 anos de plantio direto, as características físicas do solo não se alteraram significativamente, em relação à área com 10 anos de cultivo, evidenciando a estabilidade do sistema, porém diferiu da área de mata.

Palavras-chaves: Plantio direto; Densidade; Macroporosidade; Microporosidade; Porosidade total.

Abstract

With the increase of the years of implantation of direct soil system, soil physical characteristics, as the density, macroporosity, microporosity and total porosity, are modified, being scarce studies that evaluate some years of implantation of this system, in diverse soil types. The objective of this work was to compare the physical characteristics of a Dark Red oxissoil under different periods of direct soil system installation, with a native forest as control, in the region of Campo Mourao, Parana State. The data collection was carried out in four areas, with one hectare each, with 10, 20 and 30 years of direct soil system implantation and one of native forest. The intact sample for the physical analysis was removed in the depths of 0-5; 5-10; 10-15; and 15-20 $\mathrm{cm}$. It was observed, in the area with 30 years of direct soil system, that the soil physical characteristics had not changed significantly, in relation to the area with 10 years of culture, keeping the system stability, however it differed from the forest area.

Keywords: Direct soil system; Density; Macroporosity; Microporosity; Total porosity.

Doutorando do Programa de Pós-Graduação em Agronomia, Área de Concentração: Produção Vegetal - UFPR; Professor Adjunto da PUCPR; renato.tratch@pucpr.br;

2 Doutora do Departamento de Solos e Engenharia Rural - UFPR;

Engenheira Agrônoma; tatimontans@hotmail.com;

4 Professor Adjunto do Curso de Agronomia da PUCPR, Centro de Ciências Agrárias e Ambientais, PUCPR, BR376, km 14, CP 129, CEP 83010-500, São José dos Pinhais, PR, airton.junior@pucpr.br 


\section{Introdução}

O plantio direto foi introduzido no Brasil nos anos 70 e baseia-se na manutenção de palha na superfície, no aumento da atividade biológica, no menor revolvimento possível do solo, rotação de culturas e intenso tráfego de máquinas nas operações de pulverização, semeadura e colheita e no uso dos recursos naturais para aumentar a produção e reduzir os custos.

Com o aumento dos anos de implantação do sistema de plantio direto, assim como as características químicas e físicas como a densidade, macroporosidade, microporosidade e porosidade total, são alteradas, (SÁ, 1993; TORMENA et al., 2004).

Enquanto Stone e Silveira (2001) indicam que a interação entre os anos de cultivo e as propriedades físicas do solo no sistema plantio direto proporciona maiores valores de densidade e microporosidade e, em conseqüência, menor porosidade total e macroporosidade, Secco et.al. (2005) verificaram que os valores de densidade, porosidade total e macroporos no sistema de plantio direto permaneceram praticamente constantes, em três anos consecutivos e nas profundidades de $0-7 ; 7-14 ; 14-20 \mathrm{~cm}$, não indicando tendência de adensamento no tempo. Os resultados do trabalho de Goedert et. al. (2002) revelaram que não foi observada compactação do solo na área cultivada pelo sistema de plantio direto após sete anos de cultivo, mostrando que o adequado manejo do solo pode minimizar ou mesmo eliminar os efeitos compactantes advindos do tráfego de máquinas e implementos agrícolas.

O objetivo deste trabalho foi comparar as características físicas de um Latossolo Vermelho Escuro sob diferentes períodos de instalação do sistema de plantio direto com uma área controle sob mata nativa, na região de Campo Mourão, Paraná.

\section{Material e métodos}

O experimento foi conduzido na região de Campo Mourão, situado a 240ㅡ'38' de Latitude Sul e 52²2'40' de Longitude Oeste do Meridiano de Greenwich, a uma altitude média de 630 metros sobre o nível do mar.

O clima do Município de Campo Mourão é classificado como Cfa: Clima subtropical úmido mesotérmico. A média das temperaturas dos meses mais quentes é superior a $22^{\circ} \mathrm{C}$ e a dos meses mais frios é inferior a $18^{\circ} \mathrm{C}$. Os índices pluviométricos apresentam-se em média entre $1.400 \mathrm{~mm}$ e $1.500 \mathrm{~mm}$ por ano, tendo nos meses de verão as maiores concentrações de chuvas e nos meses de inverno as menores (PREFEITURA DE CAMPO MOURÃO, 2004).

As áreas estudadas se localizam no terceiro planalto e apresentam como vegetação predominante floresta subtropical perenifólia de araucária. O solo é classificado como Latossolo Vermelho Escuro, com relevo suave ondulado a ondulado, textura argilosa, drenagem moderada a bem drenada e de fertilidade natural baixa.

A coleta dos dados foi realizada em quatro áreas de um hectare, que apresentam diferentes períodos de implantação do sistema de plantio direto: 10, 20 e 30 anos e uma de mata nativa, com as características químicas apresentadas nas Tabelas 1 e 2. Todas as áreas tiveram um programa de rotação de culturas conforme Quadro 1. A calagem foi realizada em todas as áreas, antes da implantação da aveia preta, respeitando-se a necessidade de cada área, e apresentando média de 2,48 T.ha-1 . 
TABELA 1 - Análise química nas profundidades de 0 - 2,5; 2,5 - 5; 5 - 10; 10 - $20 \mathrm{~cm}$, nas áreas de mata nativa, 10, 20 e 30 anos de implantação do sistema de plantio direto, na região de Campo Mourão - PR.

Table 1 - Chemical analysisin the depths of 0 - 2.5; $2.5-5 ; 5-10 ; 10$ - $20 \mathrm{~cm}$, in the areas of native forest, 10, 20 and 30 years of implantation of the direct soil system, in the Campo Mourao Region - PR.

\begin{tabular}{|c|c|c|c|c|c|c|c|c|c|c|c|}
\hline & Profundidade & pH & Al & Ca & Mg & $\mathbf{K}$ & СTC & $\mathbf{P}$ & V & $\mathbf{m}$ & M.O. \\
\hline Área & $\mathbf{c m}$ & $\mathrm{CaCl}_{2}$ & \multicolumn{5}{|c|}{$\mathrm{cmol}_{\mathrm{c}} \cdot \mathrm{dm}^{-3}$} & $\mathrm{mg} \mathrm{dm}^{-3}$ & \multicolumn{3}{|c|}{$\%$} \\
\hline Mata & $0-2,5$ & 3,94 & 0,8 & 1,80 & 0,90 & 0,28 & 16,4 & 3,06 & 18,19 & 21,16 & 6,13 \\
\hline \multirow[t]{3}{*}{ Nativa } & $2,5-5,0$ & 3,93 & 1,8 & 1,50 & 1,30 & 0,19 & 17,6 & 2,06 & 17,04 & 37,58 & 6,31 \\
\hline & $5,0-10,0$ & 3,83 & 2,1 & 0,80 & 0,20 & 0,15 & 14,5 & 1,73 & 7,95 & 64,62 & 5,44 \\
\hline & $10,0-20,0$ & 3,95 & 2 & 0,35 & 0,15 & 0,12 & 12,8 & 1,22 & 4,85 & 76,34 & 4,43 \\
\hline \multirow[t]{4}{*}{10 Anos } & $0-2,5$ & 5,27 & 0 & 5,40 & 1,80 & 0,53 & 13,2 & 7,24 & 58,78 & 0 & 4,97 \\
\hline & $2,5-5,0$ & 5,29 & 0 & 5,70 & 1,90 & 0,46 & 13,8 & 3,45 & 58,53 & 0 & 4,63 \\
\hline & $5,0-10,0$ & 5,41 & 0 & 5,40 & 2,10 & 0,40 & 13,2 & 2,90 & 60,03 & 0 & 4,43 \\
\hline & $10,0-20,0$ & 5,20 & 0 & 4,40 & 1,70 & 0,32 & 12,3 & 1,63 & 52,24 & 0 & 3,96 \\
\hline \multirow[t]{4}{*}{20 Anos } & $0-2,5$ & 6,40 & 0 & 5,10 & 1,90 & 0,82 & 14,1 & 15,87 & 76,63 & 0 & 5,50 \\
\hline & $2,5-5,0$ & 5,23 & 0 & 4,40 & 2,10 & 0,46 & 13,3 & 8,46 & 52,41 & 0 & 4,76 \\
\hline & $5,0-10,0$ & 5,11 & 0 & 4,00 & 1,50 & 0,39 & 12,5 & 10,69 & 47,16 & 0 & 4,36 \\
\hline & $10,0-20,0$ & 4,90 & 0 & 2,80 & 1,20 & 0,27 & 11,1 & 4,01 & 38,43 & 0 & 3,89 \\
\hline \multirow[t]{4}{*}{30 Anos } & $0-2,5$ & 5,49 & 0 & 4,55 & 1,95 & 0,44 & 12,3 & 10,24 & 56,71 & 0 & 4,16 \\
\hline & $2,5-5,0$ & 5,20 & 0 & 4,00 & 1,60 & 0,29 & 12,0 & 7,96 & 49,15 & 0 & 3,62 \\
\hline & $5,0-10,0$ & 4,99 & 0 & 3,55 & 1,45 & 0,23 & 12,1 & 7,24 & 43,15 & 0 & 3,52 \\
\hline & $10,0-20,0$ & 5,19 & 0 & 2,90 & 1,60 & 0,10 & 10,7 & 3,79 & 42,85 & 0 & 2,75 \\
\hline
\end{tabular}


TABELA 2 - Resultados da análise de micronutrientes nas profundidades de 0 - 2,5; 2,5 - 5; 5 10; 10 - $20 \mathrm{~cm}$, nas áreas de mata nativa, 10, 20 e 30 anos de implantação do sistema de plantio direto, na região de Campo Mourão - PR.

Table2 - Micronutrients results from analysisin the depths of $0-2.5 ; 2.5-5 ; 5-10 ; 10-20 \mathrm{~cm}$, in theareas of native forest, 10, 20 and 30 years of implantation of the direct soil system, in the Campo Mburao Region - PR.

\begin{tabular}{|c|c|c|c|c|c|}
\hline Área & $\begin{array}{l}\text { Profundidade } \\
\text { cm }\end{array}$ & $\mathrm{Cu}$ & \multicolumn{3}{|c|}{$\mathrm{mg} . \mathrm{dm}^{-3}$} \\
\hline \multirow[t]{4}{*}{ Mata Nativa } & $0-2,5$ & 2,5 & 3,94 & 58,2 & 151,2 \\
\hline & $2,5-5,0$ & 3,2 & 1,94 & 69,3 & 92,0 \\
\hline & $5,0-10,0$ & 3,3 & 1,63 & 79,0 & 61,5 \\
\hline & $10,0-20,0$ & 5,1 & 8,83 & 95,6 & 25,1 \\
\hline \multirow[t]{4}{*}{10 anos } & $0-2,5$ & 3,5 & 2,31 & 22,0 & 91,2 \\
\hline & $2,5-5,0$ & 3,5 & 1,46 & 12,8 & 108,0 \\
\hline & $5,0-10,0$ & 3,6 & 0,86 & 17,9 & 95,2 \\
\hline & $10,0-20,0$ & 4,1 & 4,99 & 27,4 & 72,5 \\
\hline \multirow[t]{4}{*}{20 Anos } & $0-2,5$ & 1,7 & 2,65 & 24,3 & 101,6 \\
\hline & $2,5-5,0$ & 3,5 & 2,47 & 20,1 & 79,4 \\
\hline & $5,0-10,0$ & 4,0 & 4,21 & 26,6 & 75,6 \\
\hline & $10,0-20,0$ & 4,6 & 4,38 & 36,4 & 50,6 \\
\hline \multirow[t]{4}{*}{30 Anos } & $0-2,5$ & 3,4 & 1,65 & 64,6 & 53,8 \\
\hline & $2,5-5,0$ & 3,6 & 1,50 & 50,6 & 50,0 \\
\hline & $5,0-10,0$ & 4,4 & 1,44 & 30,6 & 48,6 \\
\hline & $10,0-20,0$ & 5,2 & 1,09 & 35,8 & 35,0 \\
\hline
\end{tabular}

QUADRO 1 - Rotacão de culturas nos anos de 2001, 2002, 2003 e 2004, realizadas nas áreas de 10, 20 e 30 anos de implantação do sistema de plantio direto, na Região de Campo Mourão-PR. Chart 1 - Crop rotation in the years of 2001,2002, 2003 and 2004, carried out in the areas of 10, 20 and 30 years of implantation of the direct soil system, in the Campo Mourao Region -PR.

\begin{tabular}{|c|c|c|c|c|c|c|c|}
\hline \multicolumn{8}{|c|}{ Safra } \\
\hline Área & $\begin{array}{l}\text { Verão } \\
\text { 00/01 }\end{array}$ & $\begin{array}{c}\text { Inverno } \\
2001\end{array}$ & $\begin{array}{l}\text { Verão } \\
\text { 01/02 }\end{array}$ & $\begin{array}{c}\text { Inverno } \\
2002\end{array}$ & $\begin{array}{l}\text { Verão } \\
\text { 02/03 }\end{array}$ & $\begin{array}{c}\text { Inverno } \\
2003\end{array}$ & $\begin{array}{l}\text { Verão } \\
\text { 03/04 }\end{array}$ \\
\hline 10 Anos & Soja & Aveia Preta & Milho & Trigo & Soja & Trigo & Soja \\
\hline 20 Anos & Soja & Trigo & Soja & Trigo & Soja & Aveia Preta & Milho \\
\hline 30 Anos & Soja & Trigo & Soja & Aveia Preta & Milho & Aveia Branca & Soja \\
\hline
\end{tabular}


Foram coletadas amostras de seis pontos, cada um representando uma repetição, nas quais foram realizadas as análises físicas. A análise química foi realizada com uma amostra composta dos seis pontos. A retirada das amostras intactas foi efetuada com o auxilio do amostrador (cachimbo) e anéis volumétricos de $5 \mathrm{~cm}$ de altura e $5 \mathrm{~cm}$ de diâmetro. Para cada repetição as profundidades de coleta foram: 0 - 5; 5 - 10; 10 - 15; e 15 - $20 \mathrm{~cm}$. Após a coleta, a base e o topo dos anéis foram fechados com tecido absorvente e elástico. Acondicionadas em sacos plásticos, identificadas e mantidas sob temperatura de $\pm 5^{\circ} \mathrm{C}$, sendo em seguida encaminhados ao laboratório.

Os parâmetros avaliados foram: a densidade do solo, porosidade total, macroporosidade, microporosidade, segundo metodologia da EMBRAPA (1997).

Os dados foram submetidos à análise de variância e as médias comparadas pelo teste de Turkey a $5 \%$ de probabilidade.

\section{Resultados e discussão}

A análise de solo (TABELA 1) apresenta valores diferentes entre a área de mata nativa e as áreas de cultivo de plantio direto. Considerando a interpretação, segundo SBCS (2004), a área de mata nativa a matéria orgânica, acidez, pH e alumínio apresentam níveis mais elevados do que as áreas de plantio direto. Porém o inverso se observa para cálcio, magnésio, potássio e fósforo, caracterizando os incrementos realizados com as calagens e adubações nas áreas cultivadas. Os micronutrientes $\mathrm{Cu}, \mathrm{Zn}, \mathrm{Mn}$ e Fe (Tab. 2) apresentam níveis elevados, de acordo com SBCS, 2004), tanto na área de mata nativa quando nas de plantio direto.

A densidade do solo apresentou diferença estatística, na mesma profundidade, significativa entre a área de mata nativa e as áreas cultivadas, como pode ser observado na figura 1. A área de mata nativa apresentou os menores valores de densidade em todas as profundidades avaliadas e o tempo da adoção do sistema apresentou os maiores valores. Esses se encontram níveis próximos aos encontrados por Oliveira et al. (2004) em Latossolo Vermelho, sob cerrado, com 20 anos de plantio direto. A densidade maior nestas áreas, do que na área de mata, ocorre normalmente devido ao intenso tráfego de máquinas, nas operações de pulverização, plantio e colheita, utilizados em condições desfavoráveis de solo e umidade (GOEDERT et. al., 2002). Segundo Stone e Silveira (2001), o cultivo em sistema de plantio direto aumenta a densidade e a microporosidade e em conseqüência diminui a porosidade total e a macroporosidade.

FIGURA 1 - Densidade do solo nas profundidades de 0 - 2,5; 2,5 - 5; 5 - 10; 10 - $20 \mathrm{~cm}$, nas áreas de mata nativa, 10, 20 e 30 anos de implantação do sistema de plantio direto, na região de Campo Mourão - PR.

Figure 1 - Soil density in the depths of 0 - 2.5; 2.5 - 5; 5 - 10; 10 - $20 \mathrm{~cm}$, in the areas of native forest, 10, 20 and 30 years of implantation of the direct soil system, in the Campo Mourao Region - PR.

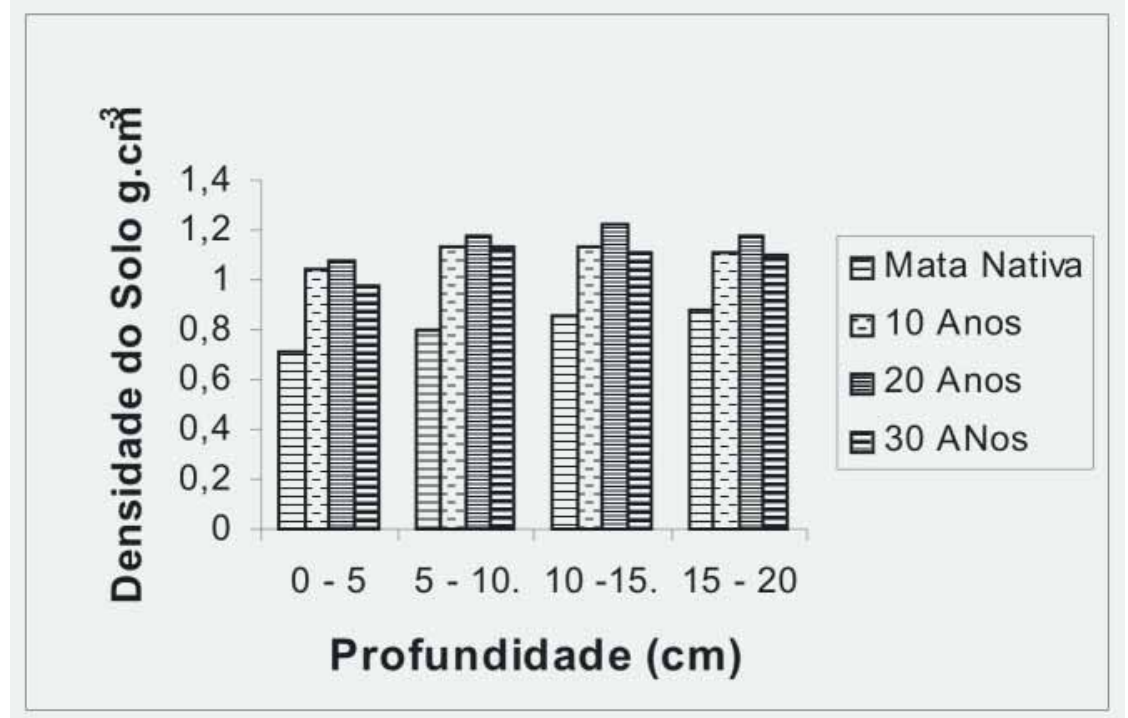

Rev. Acad., Curitiba, v.4, n.1, p. 71-79, jan./mar. 2006. 
A profundidade de 0 a $5 \mathrm{~cm}$ foi a que apresentou, independente do tempo de instalação do sistema e incluindo a área de mata, a menor densidade. Segundo Assis e Lanças (2005), tal fato se deve ao maior teor de matéria orgânica nesta profundidade, o que favorece a diminuição da densidade pela sua maior estruturação.

A macroporosidade (FIGURA 2) apresentou diferença estatística apenas entre a área de mata nativa e as áreas cultivadas. Na área de mata nativa, a macroporosidade apresentou queda de
$6 \%$ da profundidade de $0-5$ para a de $15-20$ $\mathrm{cm}$. As áreas cultivadas apresentaram maior porcentagem de macroporos nos primeiros $5 \mathrm{~cm}$, diminuindo posteriormente nas demais profundidades, as quais mantiveram quantidades de macroporos próximas uma das outras, não diferindo estatisticamente, assemelhando-se aos resultados obtidos por Secco et. al. (2005). Esta maior quantidade na camada superficial provavelmente é resultado do maior teor de matéria orgânica no solo (TABELA 1).

FIGURA 2 - Resultados da análise de macroporosidade do solo nas profundidades de 0 - 2,5; 2,5 - 5; 5 - 10; 10 - $20 \mathrm{~cm}$ nas áreas de mata nativa, 10, 20 e 30 anos de implantação do sistema de plantio direto na região de Campo Mourão - PR.

Figure 2 - Results of soil macroporosity analysis in depths of $0-2.5 ; 2.5-5 ; 5-10 ; 10-20 \mathrm{~cm}$, in the area of native forest, 10, 20 and 30 years of implantation of the direct soil system, in the Campo Mburao Region - PR.

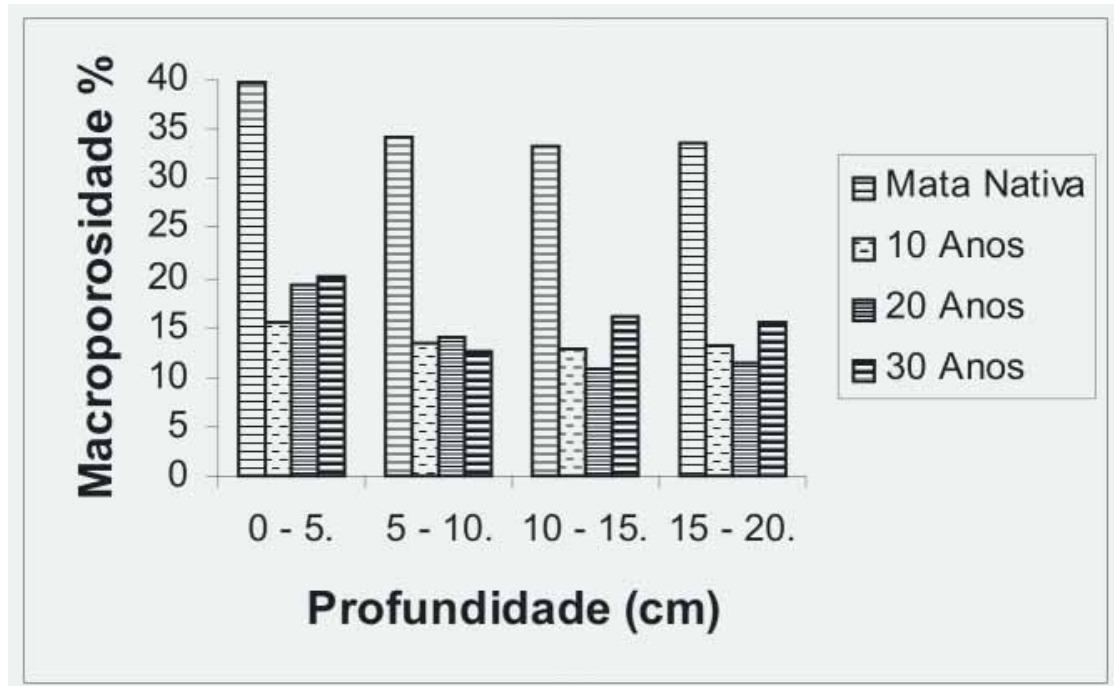

A microporosidade do solo (FIGURA 3) apresentou diferença estatística entre a área de mata nativa e as áreas cultivadas. As áreas de mata nativa, 10 e 20 anos apresentaram um aumento da microporosidade com o aumento da profundidade. Com relação aos anos de cultivo, a porcentagem de microporos apresentou oscilação entre os resultados das áreas, não tendo ocor- rido aumento desses como era esperado, conforme observado por Bertolino et al. (2003) em um Latossolo Vermelho Amarelo. Esses resultados indicam que, com a implantação do sistema de plantio direto, a relação de microporos se mantém em um nível constante, não sendo possível identificar tendência de adensamento gradual do solo (SECCO et al. 2005). 
FIGURA 3 - Resultados da análise de microporosidade do solo nas profundidades de 0 - 2,5; 2,5 - 5; 5 - 10; 10 - $20 \mathrm{~cm}$, nas áreas de mata nativa, 10, 20 e 30 anos de implantação do sistema de plantio direto, na região de Campo Mourão - PR.

Figure 3 - Results of soil microporosity analysis in the depths of $0-2.5 ; 2.5-5 ; 5-10 ; 10-20 \mathrm{~cm}$, in the area of native forest, 10, 20 and 30 years of implantation of the direct soil system, in the Campo Mourao Region - PR.

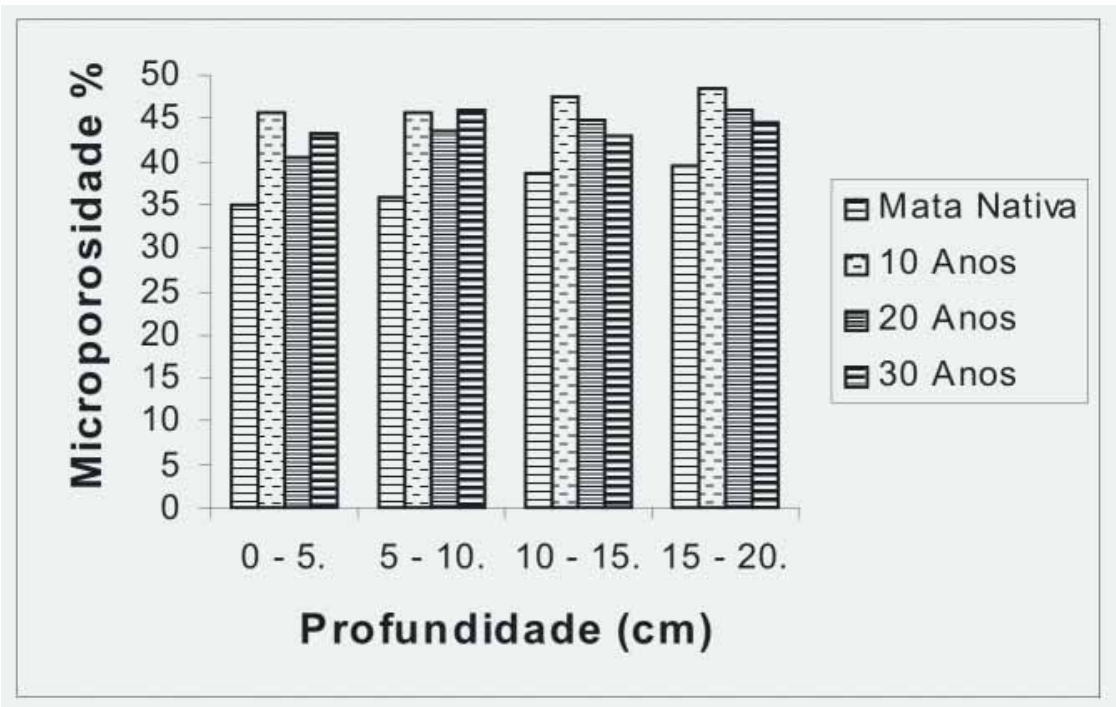

Segundo Kiehl (1979), o solo ideal é aquele que contém $1 / 3$ de macroporos (33\%) e 2/3 de microporos (67\%). Considerando a relação da microporosidade e da macroporosidade nas quatro áreas, nas quatro profundidades, pode-se dizer que os solos se encontram numa situação distante da ide$\mathrm{al}$, incluindo a área de mata nativa, a qual é a única que se aproxima dos valores de macroporosidade, o que deixa as áreas a uma situação distante da capacidade de retenção de água adequada.

Verifica-se que a microporosidade apresenta em todas as profundidades valores maiores que a macroporosidade, sendo que o comportamento da porosidade total é similar ao da macroporosidade. Esses resultados sugerem que o comportamento da dinâmica da água no solo será mais condicionado pela macroporosidade do que pela microporosidade (BERTOLINO et al., 2003).

A porosidade total (FIGURA 4) apresentou diferença estatística apenas entre a área de mata nativa e as áreas cultivadas. Em todas as áreas a porcentagem da porosidade total baixou quando comparada à camada superficial, de 0 - $5 \mathrm{~cm}$, com as demais profundidades. 
FIGURA 4 - Resultados da análise de porosidade total do solo nas profundidades de 0 - 2,5; 2,5 - 5; 5 - 10; 10 - $20 \mathrm{~cm}$ nas áreas de mata nativa, 10, 20 e 30 anos de implantação do sistema de plantio direto, na região de Campo Mourão - PR.

Figure 4 - Results of soil total porosity analysis in the depths of $0-2.5 ; 2.5-5 ; 5-10 ; 10-20 \mathrm{~cm}$, in the area of native forest, 10, 20 and 30 years of implantation of the direct soil system, in the Campo Mourao Region - PR.

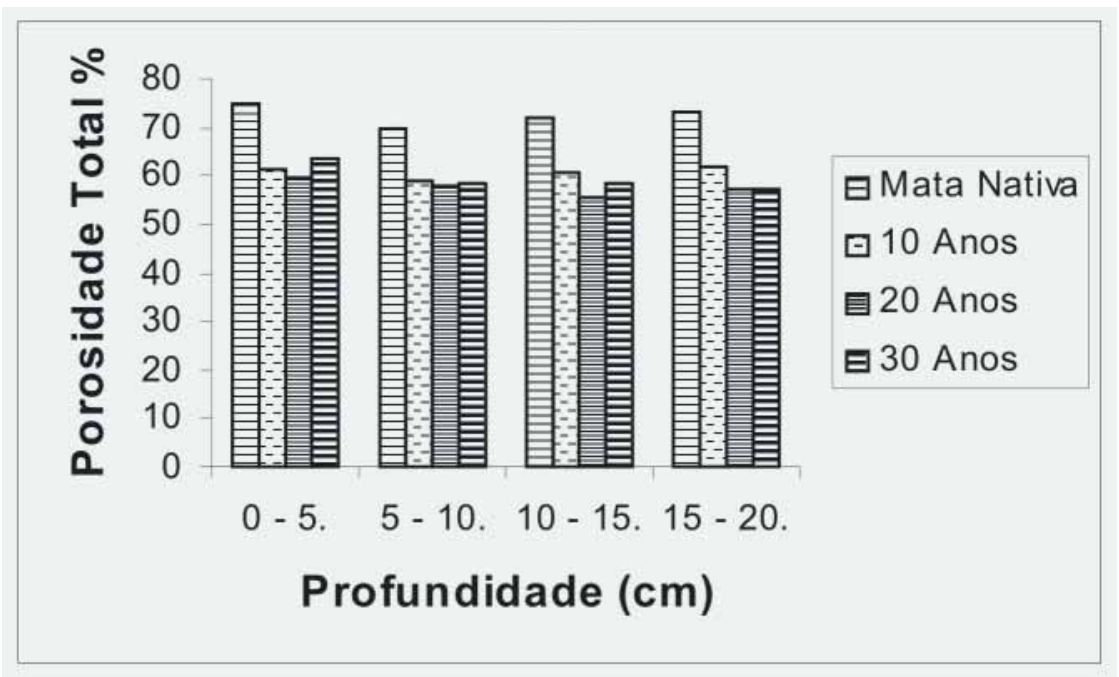

O sistema de plantio direto, analisado nesse período de tempo, não apresentou diferença significativa de porosidade total, assemelhando-se aos valores obtidos por Assis e Lanças (2005). A área de mata nativa com média de $72,49 \%$ baixou para $60,62 \%$ na área de 10 anos, 57,65\% na a área de 20 anos e $59,44 \%$ na de 30 anos, indicando uma leve compactação da área de 20 anos.

Fisicamente, as áreas cultivadas apresentaram valores maiores de densidade e de microporosidade em relação à área de mata nativa, e menores de macroporosidade e porosidade total, mas não apresentaram diferença estatística significativa nos diferentes períodos de instalação do sistema de plantio direto.

A estabilidade do sistema pode ocorrer antes dos dez anos de sua implantação, pois não ocorreram alterações nesse período.

\section{Conclusões}

Há diferença nas propriedades físicas entre a área de mata nativa e as áreas cultivadas com o sistema de plantio direto, independente do tempo de implantação.
As áreas acima de dez anos de cultivo apresentam estabilização nas propriedades físicas do solo.

\section{Referências}

ASSIS, R. L; LANÇAS, K. P. Avaliação dos atributos físicos de um Nitossolo vermelho distroférrico sob sistema plantio direto, preparo convencional e mata nativa. Revista Brasileira Ciência Solo, Viçosa, v. 29, n. 4, p. 515-522, 2005.

BERTOLNO, A.V. F. A.; SOUZA, A. P.; FERNANDES, N. F. Monitoramento dos fluxos de água sob diferentes técnicas de manejo e uso: importância na analise dos processos erosivos - Campus Experimental de Avelar, RJ. In: SIMPÓSIO BRASILEIRO DE GEOGRAFIA FISICA APLICADA, 10,,Rio de Janeiro, 2003. Anais.... Rio de Janeiro de 2003. p. 2447-2453.

EMBRAPA. Manual de métodos de análises de solo. Rio de Janeiro, RJ: Serviço Nacional de Pesquisa de Solos, 1997.

GOEDERT W. J.; SCHERMACK M. J.; FREITAS F. C.de. Estado de compactação do solo em áreas cultivadas no sistema de plantio direto. Pesquisa 
Agropecuária Brasileira, Brasília, v. 37, n. 2, p. 223-227, 2002.

KIEHL, E. J. Manual de edafologia. São Paulo, SP: Ceres, 1979.

OLIVEIRA, G. C. et al. Caracterização química e físico-hídirca de um Latossolo vermelho após 20 anos de manejo e cultivo do solo. Revista Brasileira de Ciências do Solo, v. 28, p. 327-336, 2004.

PREFEITURA De Campo Mourão. Clima Disponível em <http://www.campomourao.com.br/cidade/ clima.php> Acesso em: 19 Agosto. 2004.

SÁ, J. C. M. Manejo da fertilidade do solo no plantio direto. Castro: Fundação ABC, 1993. p. 96.

SBCS - Sociedade Brasileira de Ciência do Solo. Comissão de Química e Fertilidade do Solo. Manual de adubação e calagem para os estados do Rio Grande do Sul e de Santa Catarina. 10. ed. Porto Alegre: SBCS, 2004. p. 400.
SECCO, D. et al. Atributos físicos e produtividade de culturas em um Latossolo vermelho argiloso sob diferentes sistemas de manejo. Revista Brasileira Ciência Solo, v 29. n. 3, p. 407-414. 2005.

STONE, L. F.; SILVEIRA, P. M. Efeitos do sistema de preparo e da rotação de culturas na porosidade e densidade do solo. Revista Brasileira Ciência Solo, v. 25, n. 3, p. 395-401, 2001.

TORMENA, C. A. et al. Influência de diferentes sistemas do solo nas propriedades físicas de um Latossolo vermelho distrófico. Revista Brasileira de Engenharia Agrícola e Ambiental, v. 8, n. 1, p. 65-71, 2004. 